\title{
Visible Light Photoelectrocatalytic Properties of Novel Yttrium Treated Carbon Nanotube/Titania Composite Electrodes
}

\author{
Feng-Jun Zhang, ${ }^{\dagger, \star}$ Ming-Liang Chen, ${ }^{\dagger}$ Kan Zhang, ${ }^{\dagger}$ and Won-Chun $\mathrm{Oh}^{\dagger, *}$ \\ ${ }^{\dagger}$ Department of Advanced Materials \& Science Engineering, Hanseo University, Seosan, Chungnam 356-706, Korea \\ ${ }^{*}$ E-mail:wcoh@hanseo.ac.kr \\ ${ }^{\ddagger}$ School of Materials and Chemical Engineering, Anhui University of Architecture, Anhui Hefei, P. R. China, 230022 \\ Received September 21, 2009, Accepted November 27, 2009
}

\begin{abstract}
Photoelectrocatalytic decolorization of methlene blue (MB) in the presence of two types of carbon nanotube/titania and yttrium-treated carbon nanotube/titania electrodes in aqueous solutions were studied under visible light. The prepared composite electrodes were characterized by X-ray diffraction, transmission and scanning electron microscopy, energy dispersive X-ray analysis, and photoelectrocatalytic activity. The photoelectrocatalytic performances of the supported catalysts were evaluated for the decolorization of MB solution under visible light irradiation. The results showed that yttrium incorporation enhanced the decolorization rate of MB. It was found that the photoelectrocatalytic degradation of a MB solution could be attributed to the combined effects caused by the photo-degradation of titania, the electron assistance of carbon nanotube network, the enhancement of yttrium and a function of the applied potential. The repeatability of photocatalytic activity was also tested. The presence of yttrium enhanced the hydrophillicity of yttrium-carbon nanotubes/titania electrode because more $\mathrm{OH}$ groups can be adsorbed on the surface.
\end{abstract}

Key Words: Yttrium-carbon nanotuble/titania, Electrode, Photoelectrocatalytic, Methylene blue, Visible light

\section{Introduction}

Titanium dioxide $\left(\mathrm{TiO}_{2}\right)$-induced photocatalysis is an established advanced oxidation process for the treatment of contaminated aqueous and gaseous streams. However, poor adsorption capacity, formation of rapid aggregates in a suspension and also recycling difficulties restricted the utilization of bare $\mathrm{TiO}_{2}$. Moreover, it can be excited only under illumination with UV light at wavelengths below $400 \mathrm{~nm}$ because of the large band gap $(3.2 \mathrm{eV})$ for anatase $\mathrm{TiO}_{2}$. Unfortunately, only ca. $4 \%$ of the solar radiation that reaches the Earth's surface exists in the UV region; indeed, more than $45 \%$ lies in the visible region. ${ }^{1}$ Therefore, in practical applications, attempts have been made to support $\mathrm{TiO}_{2}$ nanoparticles on porous adsorbent materials and to extend the light absorption of the photocatalysts to the visible region. $^{2-7}$

Among these materials, carbon nanotubes (CNTs) have attracted much attention and have become a very active field of research. ${ }^{8-13} \mathrm{CNTs}$, as a new class of nanomaterials, have been drawn to considerable attention for their applications as catalyst supports owing to their unique electrical properties, high chemical stability and high surface-to-volume ratio. Moreover, CNTs have a variety of electronic properties. They may also exhibit metallic conductivity as one of the many possible electronic structures. CNTs have a large electron-storage capacity (one electron for every 32 carbon atoms), ${ }^{14}$ the ability of CNT can promote the electron-transfer reactions at carbon nanotubes modified electrodes.

On the other side, previous works ${ }^{15-20}$ have also emphasized that photocatalytic (PC) activity of $\mathrm{TiO}_{2}$ can be improved by doping of $\mathrm{TiO}_{2}$ with transition metals. The study of $\mathrm{Choi}^{15}$ studied 21 transition metal ions doped $\mathrm{TiO}_{2}$ and found that when $\mathrm{Fe}^{3+}, \mathrm{Mo}^{5+}, \mathrm{Ru}^{3+}, \mathrm{Os}^{3+}, \mathrm{Re}^{5+}, \mathrm{V}^{4+}$ and $\mathrm{Rh}^{3+}$ were used at $0.1-0.5 \%$, a significant increase in the photo-reactivity of $\mathrm{TiO}_{2}$ samples was achieved for both chloroform oxidation and reduction. In the review of Fox and Dulay, ${ }^{16}$ oxidation states of elements were found to be important in a way that both trivalent and pentavalent ions behave as recombination centers for electron-hole pairs. Recently, it has been also demonstrated that the presence of heavy metals such as $\mathrm{Pd}, \mathrm{Au}$ and $\mathrm{Ag}$ on $\mathrm{TiO}_{2}$ can enhance the degradation efficiency of $\mathrm{PC}$ reactions. ${ }^{17-20}$ Rare earth ions $\left(\mathrm{La}^{3+}, \mathrm{Eu}^{3+}, \mathrm{Sm}^{3+}, \mathrm{Nd}^{3+}, \mathrm{Pr}^{3+}\right)$ doped $\mathrm{TiO}_{2}$ catalysts has also attracted much attention in PC processes owing to their high PC activities in the degradation of organic molecules. ${ }^{21-22} \mathrm{~A}$ recent study investigated the photoactivity of yttrium incorporated $\mathrm{TiO}_{2}$ supported ZSM- 5 catalysts. ${ }^{5}$ Yttrium incorporation enhanced the decolorization rate percentage of methyl orange. Lin and $\mathrm{Yu}$ reported the $\mathrm{PC}$ activities of mixtures of $\mathrm{TiO}_{2}$ with $\mathrm{Y}_{2} \mathrm{O}_{3}$. Their results revealed that mixtures of $\mathrm{TiO}_{2}$ with $\mathrm{Y}_{2} \mathrm{O}_{3}(0.5 \mathrm{wt} \%)$ induce higher photoactivity than pure $\mathrm{TiO}_{2}$ for the oxidation of acetone. In the study of Ismail, ${ }^{24} \mathrm{Y}_{2} \mathrm{O}_{3}$ particles were embedded into $\mathrm{Fe}_{2} \mathrm{O}_{3} / \mathrm{TiO}_{2}$ mixed oxides by sol-gel method. This ternary mixed oxide resulted in a higher photooxidation rate for EDTA than pure $\mathrm{TiO}_{2}$.

On the basis of these studies, we have attempted to prepare novel PC materials. This involves $\mathrm{TiO}_{2}$ loading on the surface of CNTs modified by $\mathrm{Y}^{3+}$ ions, which, to the best of our knowledge, was not reported before. To explore the synergism induced after $\mathrm{TiO}_{2}$ and $\mathrm{Y}_{2} \mathrm{O}_{3}$ nanoparticles are adsorbed on the CNTs surface, as prepared photocatalysts have been examined by using X-ray diffraction (XRD), surface area (BET) measurements, scanning electron microscopy (SEM) with energy dispersive X-ray analysis (EDX) techniques, and transmission electron microscopy (TEM). Performances of these new materials are tested for the $\mathrm{PC}$ decolorization of methylene blue $(\mathrm{MB}$, $\mathrm{C}_{16} \mathrm{H}_{18} \mathrm{~N}_{3} \mathrm{~S} \cdot \mathrm{Cl} \cdot 3 \mathrm{H}_{2} \mathrm{O}$ ) under visible light illumination. $\mathrm{MB}$ is a 
water-soluble azo dye, produced in textile, printing, paper manufacturing, and pulp processing and pharmaceutical industries. It is a major water pollutant in these industries and release into the environment create real problems. It was selected because under anaerobic conditions it has the potential to produce more hazardous aromatic amines. Thus, MB is selected as the probe molecule in this study and its decolorization is controlled under the effect of yttrium ion content. Besides, recycling studies are performed to test the repeatability of the photocatalysts, and the hydrophilicity of the electrodes was also studied.

\section{Experimental}

Materials. Carbon nanotubes (CNTs) were selected as the support material. The CNTs (Multiwall nanotubes, diameter: $\sim 20 \mathrm{~nm}$, length: $\sim 5 \mu \mathrm{m}$ ) were supplied from Carbon Nano-Material Technology Co., Ltd, Korea and used without further purification. The TNB $\left(\mathrm{Ti}\left(\mathrm{OC}_{4} \mathrm{H}_{7}\right)_{4}\right)$ as a titanium source for the preparation of composites was purchased from Acros Organics, New Jersey, USA. For the oxidization of the surface of the CNT, $m$-chloroperbenzoic acid (MCPBA) was used as an oxidized reagent; also purchased from Acros Organics, New Jersey, USA. Methylene blue was the analytical grade chemical and purchased from Duksan Pure Chemical Co., Ltd, Korea. Benzene $(99.5 \%$ ) was used as an organic solvent which was purchased from Samchun Pure Chemical Co., Ltd, Korea. Yttrium nitrate hexahydrate $\left(\mathrm{Y}\left(\mathrm{NO}_{3}\right)_{3} \cdot 6 \mathrm{H}_{2} \mathrm{O}\right)$ was obtained from Daejung Chemicals \& Metals Co., Ltd, Korea. The novolac typed polymer resin (PR) was supplied from Kangnam Chemical Co., Ltd, Korea. Reagent-grade solvents, benzene and ethyl alcohol, were purchased from Duksan Pure Chemical Co. and Daejung Chemical Co., Korea and used without further purification.

Preparation of Y-CNT composites. To begin preparing this experiment, the $2.0 \mathrm{~g}$ MCPBA as oxidizing agent was melted in $60 \mathrm{~mL}$ benzene. Then $0.6 \mathrm{~g}$ CNTs was put into the oxidizing agent, refluxed for $6 \mathrm{~h}$, filtered and dried. The oxidized CNTs were added to nitrate solution containing $\mathrm{Y}\left(\mathrm{NO}_{3}\right)_{3} \cdot 6 \mathrm{H}_{2} \mathrm{O}$, of various concentration, and then the solutions were homogenized under reflux at $343 \mathrm{~K}$ for $2 \mathrm{~h}$ using a magnetic stirrer in a vial. After being heat treated at $773 \mathrm{~K}$ for $1 \mathrm{~h}$ with a heating rate of $279 \mathrm{~K} / \mathrm{min}$, the $\mathrm{Y}$ treated CNT composites were obtained.

Preparation of $\mathrm{Y}-\mathrm{CNT} / \mathrm{TiO}_{2}$ composite electrodes. The $\mathrm{Y}$ treated CNT composites were put into the mixing solution of TNB and benzene with a volume ratio of $4: 16$. Then the solutions were homogenized under reflux at $343 \mathrm{~K}$ for $5 \mathrm{~h}$, while being stirred in a vial again. After stirred, the solutions transformed into $\mathrm{Y}-\mathrm{CNT} / \mathrm{TiO}_{2}$ gels, and these gels were heat treated at $973 \mathrm{~K}$ for $1 \mathrm{~h}$ with a heating rate of $279 \mathrm{~K} / \mathrm{min}$. After cooling, the $\mathrm{Y}-\mathrm{CNT} / \mathrm{TiO}_{2}$ composites were resulted. Then $0.4 \mathrm{~g}$ PR was added to the $\mathrm{Y}-\mathrm{CNT} / \mathrm{TiO}_{2}$ composites, and the composites were pressed at a pressure of $250 \mathrm{~kg} / \mathrm{cm}^{2}$ in a mould with dimensions of $9.95 \mathrm{~mm} \times 39.5 \mathrm{~mm} \times 5.95 \mathrm{~mm}$. The mixture was then heat treated at $673 \mathrm{~K}$ for $1 \mathrm{~h}$. After cooling, the $\mathrm{Y}-\mathrm{CNT} / \mathrm{TiO}{ }_{2}$ composite electrodes were obtained. The preparation conditions and the nomenclatures of the samples are showed in Fig. 1 and Table 1.

Characterization of the $\mathrm{Y}-\mathrm{CNT} / \mathrm{TiO}_{2}$ composites. XRD techinque was used for crystal phase identification and estimation

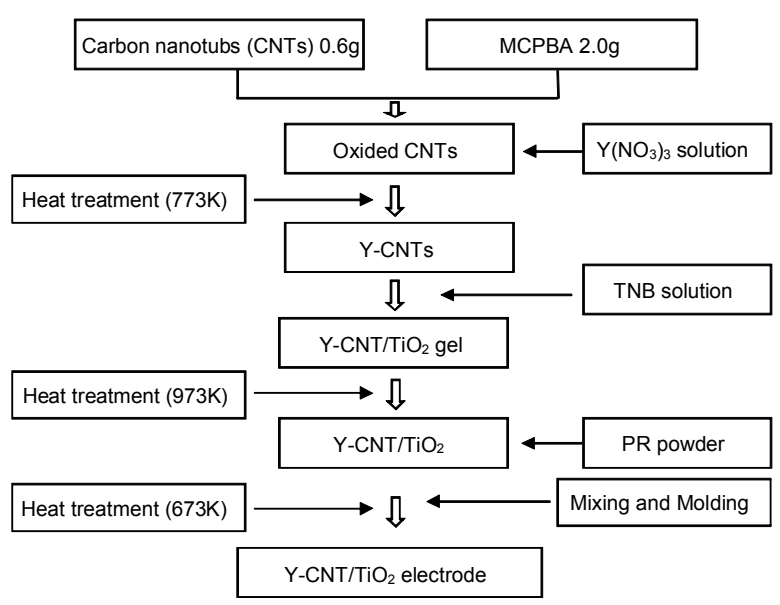

Figure 1. The flow chart of fabrication of $\mathrm{Y}-\mathrm{CNT} / \mathrm{TiO}_{2}$ electrodes.

Table 1. Nomenclatures of $\mathrm{Y}-\mathrm{CNT} / \mathrm{TiO}_{2}$ composites

\begin{tabular}{lc}
\hline \multicolumn{1}{c}{ Preparation method } & Nomenclatures \\
\hline $\begin{array}{l}2.0 \mathrm{~g} \mathrm{MCPBA}+0.6 \mathrm{~g} \mathrm{CNT}+\mathrm{TNB} 4 \mathrm{~mL} \\
2.0 \mathrm{~g} \mathrm{MCPBA}+0.6 \mathrm{~g} \mathrm{CNT}+\mathrm{Y}\left(\mathrm{NO}_{3}\right)_{3}(0.01 \mathrm{M})\end{array}$ & $\mathrm{YCT} 0$ \\
$+\mathrm{TNB} 4 \mathrm{~mL}$ & \\
$\begin{array}{l}2.0 \mathrm{~g} \mathrm{MCPBA}+0.6 \mathrm{gCNT}+\mathrm{Y}\left(\mathrm{NO}_{3}\right)_{3}(0.015 \mathrm{M}) \\
+\mathrm{TNB} 4 \mathrm{~mL}\end{array}$ & $\mathrm{YCT} 2$ \\
$\begin{array}{l}2.0 \mathrm{~g} \mathrm{MCPBA}+0.6 \mathrm{~g} \mathrm{CNT}+\mathrm{Y}\left(\mathrm{NO}_{3}\right)_{3}(0.020 \mathrm{M}) \\
+\mathrm{TNB} 4 \mathrm{~mL}\end{array}$ & $\mathrm{YCT} 3$ \\
$\begin{array}{l}2.0 \mathrm{~g} \mathrm{MCPBA}+0.6 \mathrm{gCNT}+\mathrm{Y}\left(\mathrm{NO}_{3}\right)_{3}(0.025 \mathrm{M}) \\
+\mathrm{TNB} 4 \mathrm{~mL}\end{array}$ & $\mathrm{YCT} 4$ \\
\hline
\end{tabular}

of the anastase-to-rutile ratio. XRD patterns were obtained at room temperature with a diffractometer Shimata XD-D1 (Japan) using $\mathrm{Cu} \mathrm{K} \alpha$ radiation. SEM was used to observe the surface state and porous structure of the $\mathrm{Y}-\mathrm{CNT} / \mathrm{TiO}_{2}$ composites using a scanning electron microscope (JOEL, JSM-5200, Japan). EDX spectroscopy was used to measure the elemental analysis of the Y-CNT/TiO 2 composites. TEM (JEOL, JEM-2010, Japan) at an acceleration voltage of $200 \mathrm{kV}$ was used to investigate the size and distribution of the yttrium and titanium deposits on the CNT surface of various samples. TEM specimens were prepared by placing a few drops of the sample solution on a carbon grid. In order to test the hydrophilicity of the YCT series electrodes, the time of complete wetting for a drop of MB solution on the surface of electrode was determined. The hydrophilicity of the electrodes was studied in terms of the time of complete wetting measurement by a sessile drop method using a camera (SOKDSC-T700, SONY).

Photoelectrocatalytic (PEC) decolorization of MB. The PEC decolorization was performed by using $\mathrm{Y}-\mathrm{CNT} / \mathrm{TiO}_{2}$ electrodes in a $100 \mathrm{~mL}$ glass container and then irradiating the system with visible light (8W, KLD-08L/P/N, FAWOO TECHNOLOGY), which was used at the distance of $100 \mathrm{~mm}$ from the solution in darkness box. Prior to illumination, the electrode was impregnated in the pristine MB solution in the dark for $30 \mathrm{~min}$ needed to achieve adsorption/desorption equilibrium. The counter electrode was artificial graphite (TCK, Korea), which dimension was $9.95 \mathrm{~mm} \times 39.5 \mathrm{~mm} \times 5.95 \mathrm{~mm}$. The $\mathrm{Y}-\mathrm{CNT} / \mathrm{TiO}{ }_{2}$ elec- 


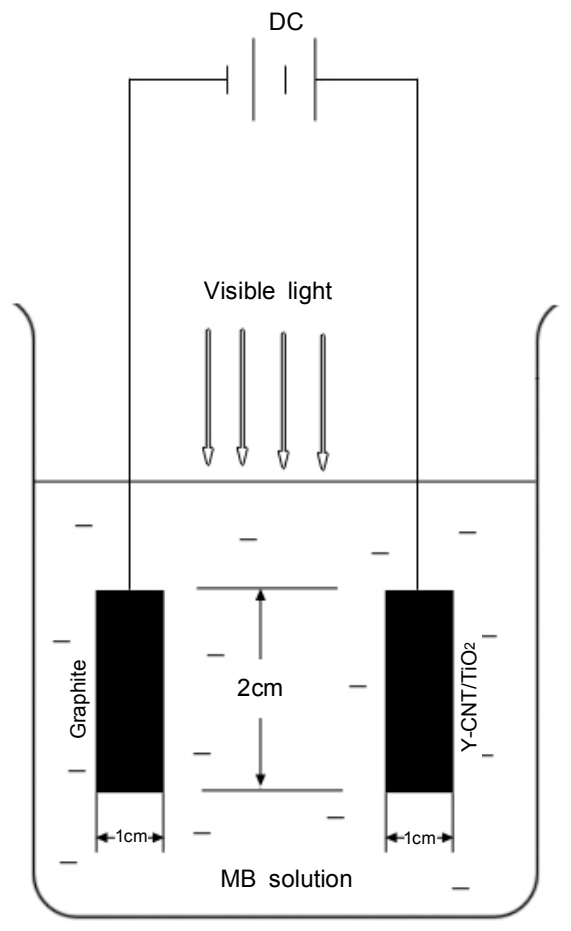

Figure 2. The sketch of PEC decomposition for MB solution with the $\mathrm{Y}-\mathrm{CNT} / \mathrm{TiO}_{2}$ electrode.

trodes were placed in $50 \mathrm{~mL}$ of $1.0 \times 10^{-5} \mathrm{~mol} / \mathrm{L} \mathrm{MB}$ solution. The PEC degradation of MB was performed with voltage of $6.0 \mathrm{~V}$ and visible light (Fig. 2). The PEC activities of Y-CNT/ $\mathrm{TiO}_{2}$ electrodes were investigated using the PEC rate of MB solution, which was measured as function of time. The blue color of the solution faded gradually with time due to the adsorption and degradation of MB solution. And then the concentration of MB in the solution was determined as a function of irradiation time from the absorbance change at a wavelength of $660 \mathrm{~nm}$. The decolorization rate of $\mathrm{MB}$ was calculated by the following equation:

$$
\text { Decolorization }(\%)=\left(\mathrm{C}_{0}-\mathrm{C}\right) / \mathrm{C}_{0} \times 100 \%
$$

Where $\mathrm{C}_{0}$ is the initial concentration of $\mathrm{MB}$ and $\mathrm{C}$ is the concentration of $\mathrm{MB}$ after " $\mathrm{t}$ " minutes visible light irradiation.

\section{Results and Discussion}

Structure and morphology of $\mathrm{Y}-\mathrm{CNT} / \mathrm{TiO}_{2}$ composites. The values of $\mathrm{BET}$ surface areas of $\mathrm{Y}-\mathrm{CNT} / \mathrm{TiO}_{2}$ composites are shown in Table 2. As shown in Table 2, the BET surface area of non-yttrium treated $\mathrm{CNT} / \mathrm{TiO}_{2}$ was 198 , while the $\mathrm{BET}$ surface areas of yttrium treated $\mathrm{CNT} / \mathrm{TiO}_{2}$ composites decreased gradually from 172 to $119 \mathrm{~m}^{2} / \mathrm{g}$ with an increase of $\mathrm{Y}\left(\mathrm{NO}_{3}\right)_{3}$ concentration. At the same addition of TNB, it was thought that the intensity of the $\mathrm{Y}$ particle aggregation increased with the increase of $\mathrm{Y}\left(\mathrm{NO}_{3}\right)_{3}$ concentration. These particles were heavily agglomerated to gather into a blocky-shaped particle. These results can be seen clearly from SEM images obtained from pow-
Table 2. Surface areas of $\mathrm{Y}-\mathrm{CNT} / \mathrm{TiO}_{2}$ composites.

\begin{tabular}{cc}
\hline Sample & $\mathrm{S}_{\text {BET }}\left(\mathrm{m}^{2} / \mathrm{g}\right)$ \\
\hline YCT0 & 198 \\
YCT1 & 172 \\
YCT2 & 141 \\
YCT3 & 129 \\
YCT4 & 119 \\
\hline
\end{tabular}

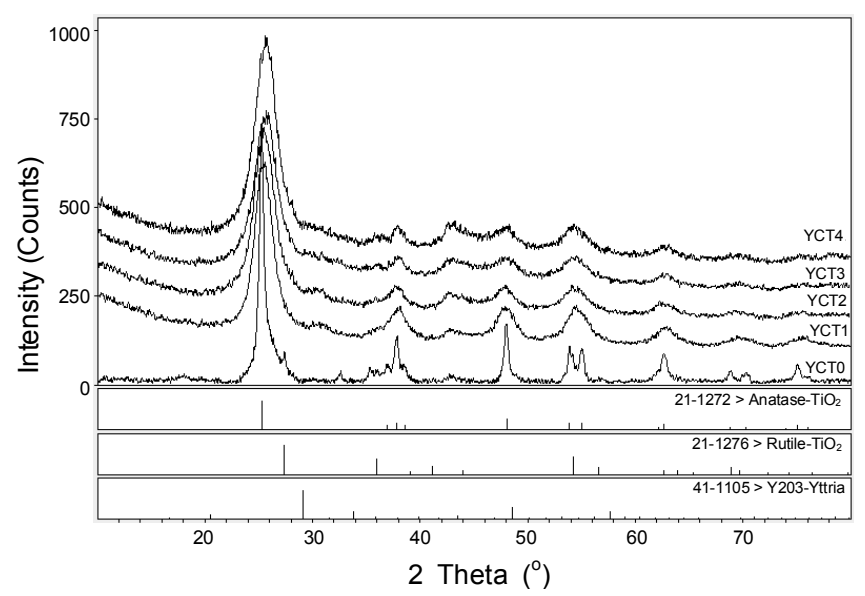

Figure 3. XRD patterns of $\mathrm{Y}-\mathrm{CNT} / \mathrm{TiO}_{2}$ composites.

dered $\mathrm{Y}-\mathrm{CNT} / \mathrm{TiO}_{2}$ composites. The results showed that there is a decrease in the BET surface area of the $\mathrm{Y}-\mathrm{CNT} / \mathrm{TiO}_{2}$ composites after formation of $\mathrm{Y}$ particles by $\left.\mathrm{Y}_{(\mathrm{NO}}\right)_{3}$ treatment. This was suggested that some porosity was developed during the heat treatment. It was thought that the composites are nano materials that include a lot of micropores. It was thought that there are two possible reasons. First, it could be attributed to the micropores being partly blocked by the formation of Y particles on the $\mathrm{CNT} / \mathrm{TiO}_{2}$ surface during heat treatment. Second, the BET surface area decreased due to the curing of polymer resin with heat treatment, which blocked the micropores and formed some new mesopores. It was possible that the phenol resin had coated some $\mathrm{CNT} / \mathrm{TiO}_{2}$ particles to form some larger composite particles during the curing process. As expected, the BET surface area is thought to decrease due to the blocking of the micropores by surface complexes introduced through the formation of Y-CNT/ $\mathrm{TiO}_{2}$ composites.

The XRD results for the catalyst samples are shown in Fig. 3. The structure of the non yttrium treated $\mathrm{CNT} / \mathrm{TiO}_{2}$ composites (YCT0) showed a mix of anatase and rutile crystals. It is well known that the crystal structure of the titanium dioxide is mainly determined by the heat treated temperature. The peaks at 25.3 , $37.8,48.0$ and $62.5^{\circ}(2 \theta)$ are the diffractions of (101), (004), (200) and (204) planes of anatase, indicating the developed $\mathrm{CNT} / \mathrm{TiO}_{2}$ composites existed in an anatase state. The peaks at $27.4,36.1,41.2$ and $54.3^{\circ}(2 \theta)$ belong to the diffraction peaks of (110), (101), (111) and (211) of rutile. Therefore, it can be concluded that the developed $\mathrm{CNT} / \mathrm{TiO}_{2}$ composites had a mixing structure of anatase and rutile crystals when annealed at $973 \mathrm{~K}$. According to the published paper, if the anatase phase is 

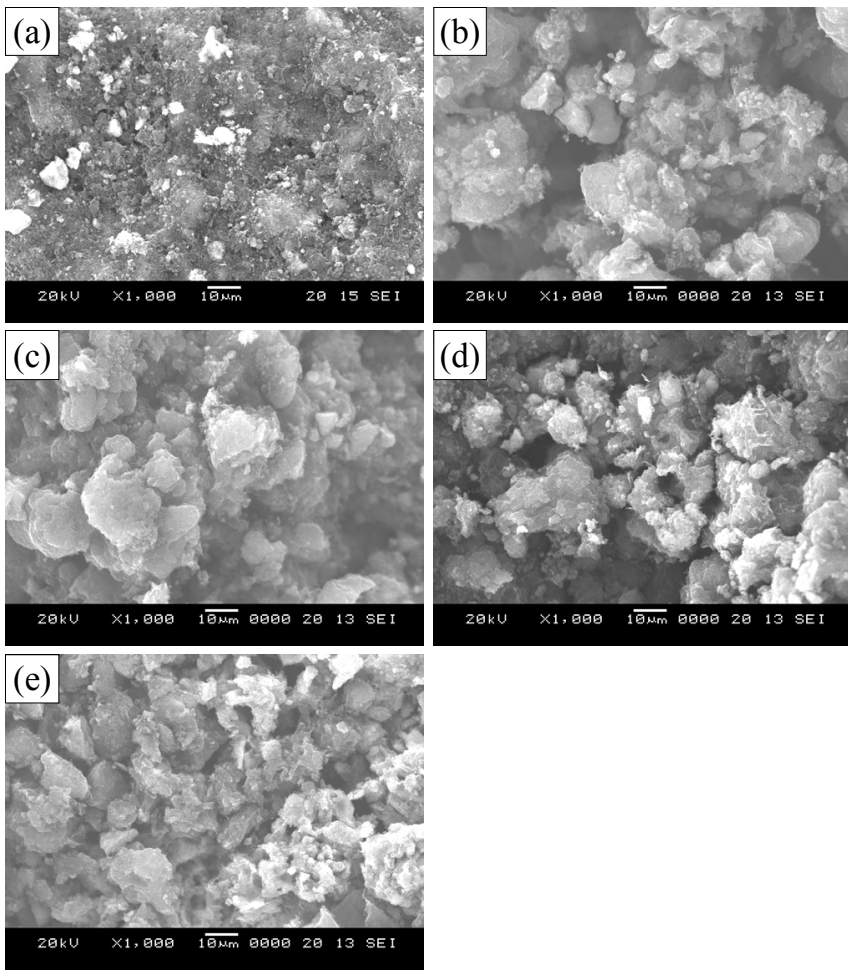

Figure 4. SEM images obtained from powdered $\mathrm{Y}-\mathrm{CNT} / \mathrm{TiO}_{2} \mathrm{com}-$ posites: (a) YCT0, (b) YCT1, (c) YCT2, (d) YCT3, (e)YCT4.

(a)

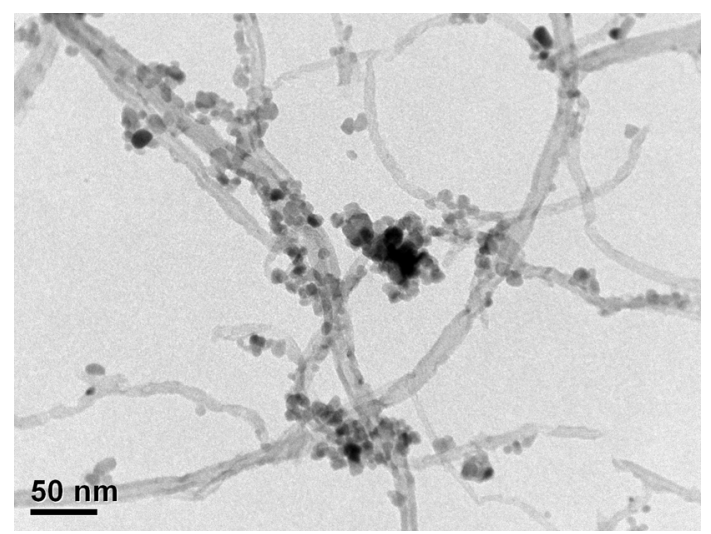

(b)

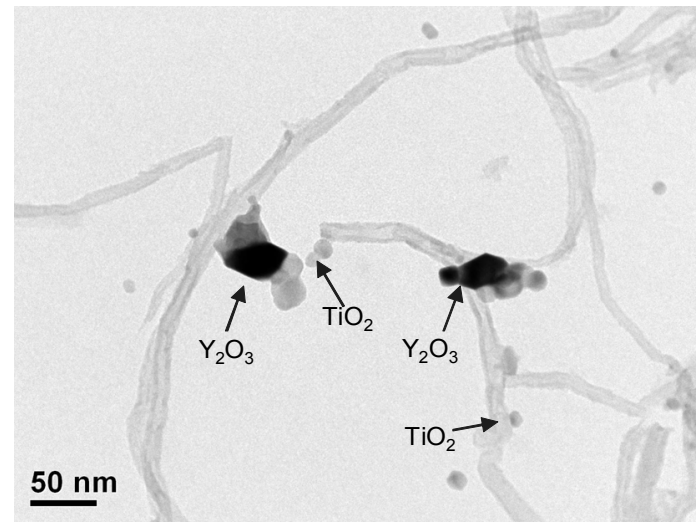

Figure 5. TEM micrographs obtained from powdered $\mathrm{CNT} / \mathrm{TiO}_{2}$ and $\mathrm{Y}-\mathrm{CNT} / \mathrm{TiO}_{2}$ composites; (a) YCT0, (b) YCT2. formed below $773 \mathrm{~K}$, it starts to transformed into a rutile-type structure above $873 \mathrm{~K}$, and then changes into a single phase of rutile at $973 \mathrm{~K} \sim 1173 \mathrm{~K} .{ }^{25}$ We have previously demonstrated that the crystallization phenomena in $\mathrm{C} / \mathrm{TiO}_{2}$ composites that are heat treated at $973 \mathrm{~K}$ results in a mixed anatase-rutile structure. ${ }^{26}$ Thus The XRD result obtained here is reasonable.

In the XRD patterns of Y-CNT/ $/ \mathrm{TiO}_{2}$ samples, formation of $\mathrm{Y}_{2} \mathrm{O}_{3}$ is searched owing to the variation of rare earth salt into rare earth oxides during the calcinations process. Although it is not

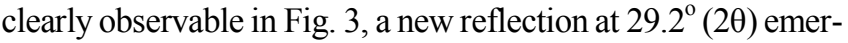
ges and indicates characteristic (222) diffraction of $\mathrm{Y}_{2} \mathrm{O}_{3}$ particles. Additional $\mathrm{Y}_{2} \mathrm{O}_{3}$ diffractions (400), (411), (134) and (440) are obtained at $33.8,35.9,43.8$ and $48.7^{\circ}(2 \theta)$, respectively. ${ }^{5}$ Intense peaks from anatase still appeared in the $\mathrm{Y}-\mathrm{CNT} / \mathrm{TiO}_{2}$ composites and became broader than that of non-yttrium treated $\mathrm{CNT} / \mathrm{TiO}_{2}$ composite with increasing concentration of the $\mathrm{Y}$ $\left(\mathrm{NO}_{3}\right)_{3}$ solution. Unfortunately, these high angle diffractions are complicated and not easily detected in the figure because of the overlapping of diffraction peaks attributed to $\mathrm{TiO}_{2}, \mathrm{Y}_{2} \mathrm{O}_{3}$ and those of the CNTs support.

The micro-surface structures and morphology of the Y-CNT/ $\mathrm{TiO}_{2}$ composites were characterized by SEM (Fig. 4) and TEM (Fig. 5). Fig. 4 shows the macroscopical changes in the morphology of the Y-CNT/ $\mathrm{TiO}_{2}$ composites. As shown in Fig. 4, the $\mathrm{TiO}_{2}$ particles were well attached to the surface of the CNT network, and the distribution was uniform. In the report of Zhang, ${ }^{27}$ a good dispersion of small particles could provide more reactive sites for the reactants than aggregated particles. At the same time, the conductive of the CNT network can facilitate the electron transfer between the adsorbed dye molecules and the catalyst substrate. ${ }^{28}$ It was beneficial for the enhancement of the PC activity of these composites. Moreover, yttrium particles were fixed on the surface of the CNT network in small clusters, and the distribution was not uniform. Moreover, we could not find the difference of the intensity of aggregation increased with the increase of $\mathrm{Y}\left(\mathrm{NO}_{3}\right)_{3}$ concentrations. These particles were heavily agglomerated to form blocky-shaped particle, and these results can be seen clearly in Fig. 4(b) to Fig. 4(d). These results are also confirmed by TEM inspection of the $\mathrm{Y}-\mathrm{CNT} / \mathrm{TiO}{ }_{2} \mathrm{com}$ posites. As shown in Fig. 5, for the $\mathrm{CNT} / \mathrm{TiO}_{2}$ composites, the $\mathrm{TiO}_{2}$ particles were distributed uniformly outside surface of CNT tube; for the $\mathrm{Y}-\mathrm{CNT} / \mathrm{TiO}_{2}$ composites, the $\mathrm{TiO}_{2}$ particles were still distributed uniformly outside surface of CNT tube, Y particles were completely attached on the surface of the tube although this caused partial agglomeration to form blockyshaped particle. However, in most cases, due to the capillary effect, ${ }^{29-30} \mathrm{Y}$ particles were formed outside the tubes, leading to poor synergic effect of the $\mathrm{Y}-\mathrm{CNT} / \mathrm{TiO}_{2}$ composites.

Fig. 6 shows the EDX spectra of $\mathrm{Y}-\mathrm{CNT} / \mathrm{TiO}_{2}$ composites prepared. From the EDX data, the main elements such as $\mathrm{C}, \mathrm{O}$, $\mathrm{Ti}$ and $\mathrm{Y}$ existed. The results of the EDX elemental microanalysis of the $\mathrm{Y}-\mathrm{CNT} / \mathrm{TiO}_{2}$ composites are listed in Table 3. The contents of the yttrium component for YCT1, YCT 2, YCT 3 and YCT 4 are $0.9,1.5,1.8$ and $2.1 \%$, respectively. It can be expected that the contents of the yttrium component in the composites increased with an increase of $\mathrm{Y}\left(\mathrm{NO}_{3}\right)_{3}$ concentrations.

PEC decolorization of MB. Fig. 7 shows the PEC decolorization rate of $\mathrm{MB}$ for different $\mathrm{Y}-\mathrm{CNT} / \mathrm{TiO}_{2}$ composite elec- 

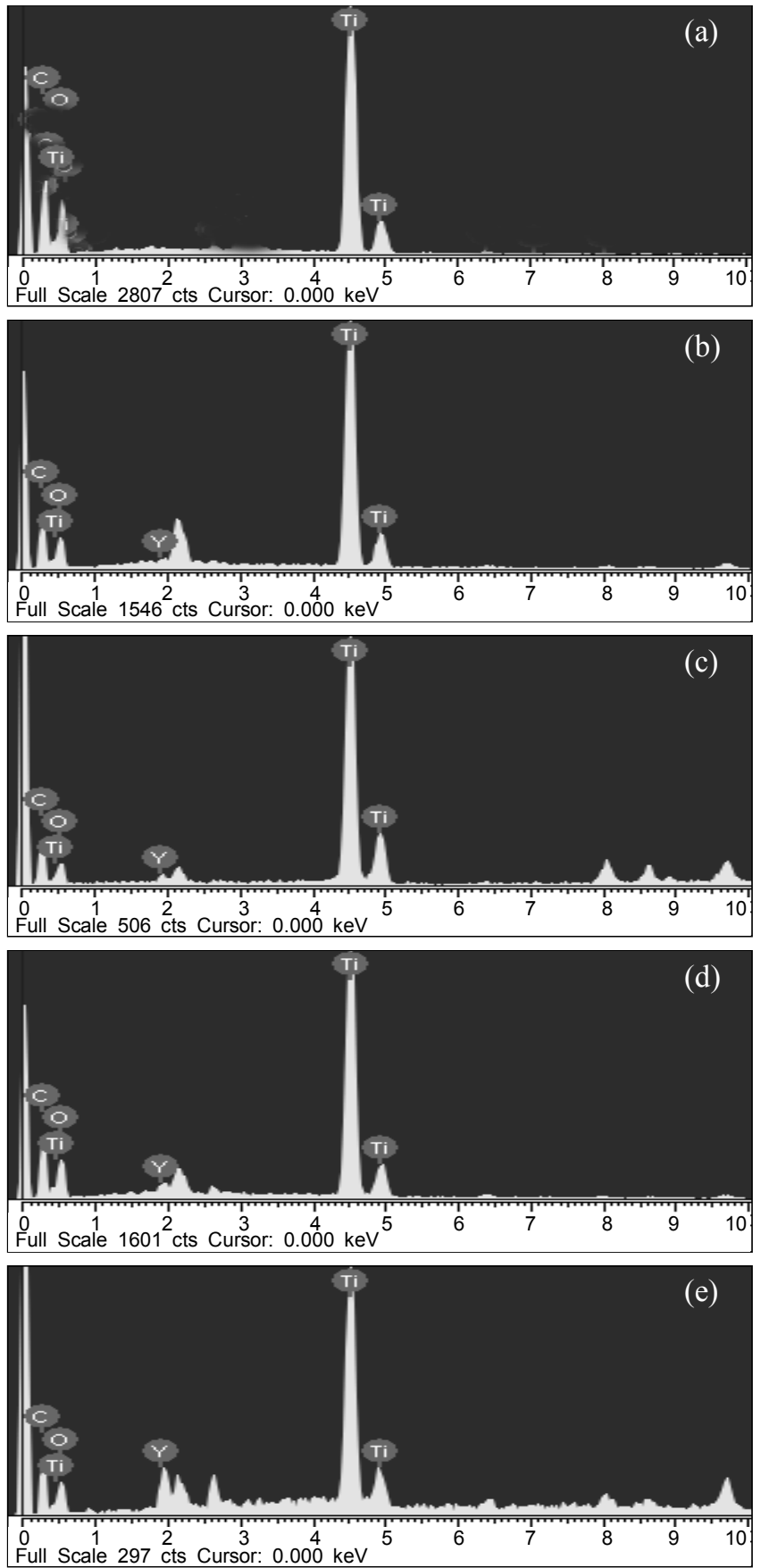

Figure 6. EDX elemental microanalysis of $\mathrm{Y}-\mathrm{CNT} / \mathrm{TiO}_{2}$ composites: (a)YCT0, (b)YCT1, (c) YCT2, (d) YCT3, (e) YCT4.

trodes under visible light irradiation with or without electron currents. Here we discussed three kinds of degradation process: 1). PEC: Visible light irradiation using the electrodes with a potential of $6.0 \mathrm{~V} ; 2$ ). PC: Visible light irradiation using the electrodes; 3). P: Only visible light irradiation. From the results present in Fig. 7, comparing with $\mathrm{CNT} / \mathrm{TiO}_{2}$ and $\mathrm{Y}-\mathrm{CNT} / \mathrm{TiO}_{2}$ composite electrodes, except YCT4, the PEC and PC effects of the $\mathrm{Y}$ treated $\mathrm{CNT} / \mathrm{TiO}_{2}$ composite electrodes were all better than that of non-Y treated $\mathrm{CNT} / \mathrm{TiO}_{2}$ in the irradiation time of 60 minutes. It was implied that the introduction of $\mathrm{Y}$ enhanced the
Table 3. EDX elemental microanalysis of $\mathrm{Y}-\mathrm{CNT} / \mathrm{TiO}_{2}$ composites

\begin{tabular}{ccccc}
\hline \multirow{2}{*}{ Samples } & \multicolumn{4}{c}{ Element (wt. \%) } \\
\cline { 2 - 5 } & $\mathrm{C}$ & $\mathrm{O}$ & $\mathrm{Ti}$ & $\mathrm{Y}$ \\
\hline YCT0 & 21.0 & 36.0 & 43.0 & 0 \\
YCT1 & 18.5 & 32.5 & 48.1 & 0.9 \\
YCT2 & 20.2 & 29.8 & 48.5 & 1.5 \\
YCT3 & 21.2 & 34.8 & 42.2 & 1.8 \\
YCT4 & 22.7 & 30.8 & 44.4 & 2.1 \\
\hline
\end{tabular}
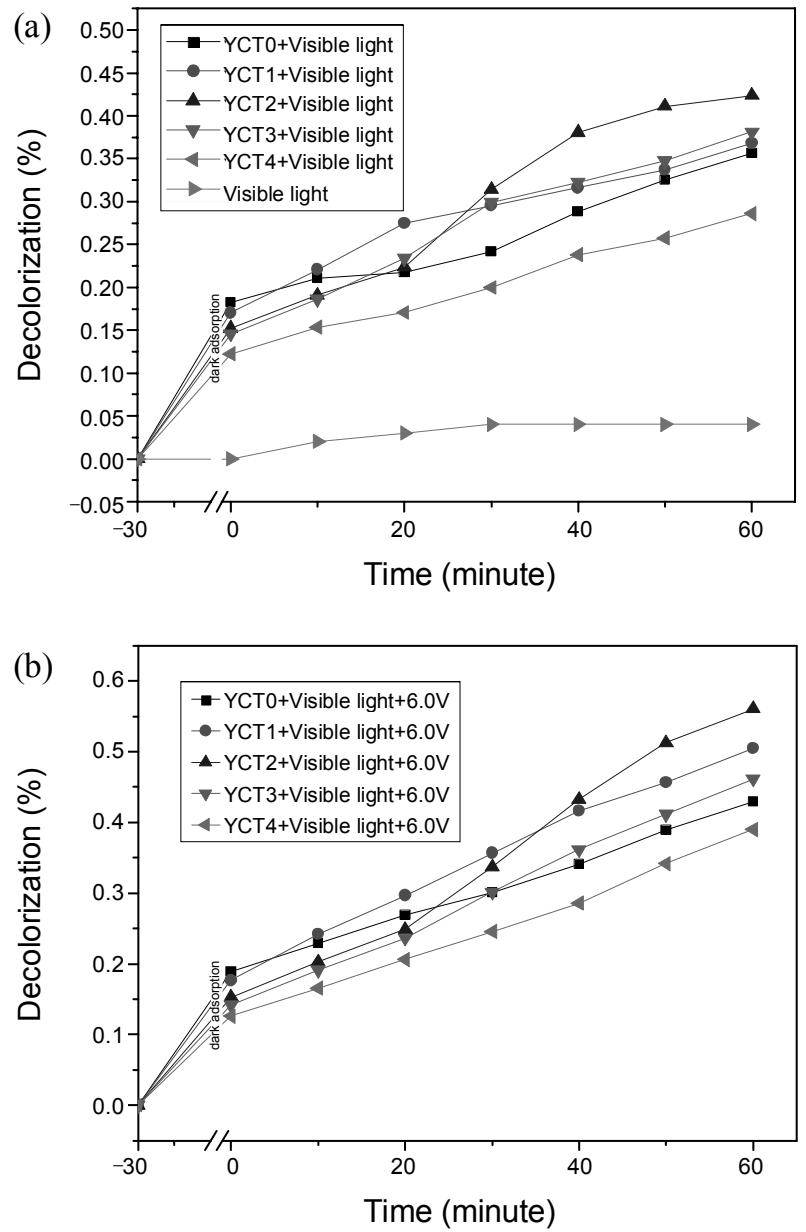

Figure 7. Effect of the photoelectrocatalytic decolorization rate of $\mathrm{MB}$ for different $\mathrm{Y}-\mathrm{CNT} / \mathrm{TiO}_{2}$ composite electrodes: (a) under visible light irradiation, (b) in a function of the applied potential of $6.0 \mathrm{~V}$ under visible light irradiation.

PEC and PC degradation of MB solution. However, for the Y treated $\mathrm{CNT} / \mathrm{TiO}{ }_{2}$ series, the PEC and PC degradation efficiency of the sample YCT2 is higher than that of the other samples in the irradiation time of 60 minutes. The electrocatalytic activity of Y particles for this reaction is dependent on various factors, which involves the size and dispersion of the particles, supporting materials and their surface conditions. In the case of YCT3 and YCT4, the Y particles were heavily agglomerated to gather into a blocky-shaped particle (see Fig.4 (d) and (e)), which leads to the significant reduction on its activity. It is well known that 
the PEC activity will increase with an increase of $Y$ content in a certain range. At the same time, the morphology of $\mathrm{Y}$ in the $\mathrm{Y}-\mathrm{CNT} / \mathrm{TiO}_{2}$ composites is an important factor. Note that the optimization of PEC decolorization of $\mathrm{MB}$ using $\mathrm{Y}-\mathrm{CNT} / \mathrm{TiO}_{2}$ composite electrodes will be studied in detail in another paper.

The repeatability of photoelectrocatalytst activity. To examine the stability of YCT2 electrode, recycling experiments are carried out (Fig. 8). For each new cycle, the photoelectrocatalyst is washed and calcined at $400{ }^{\circ} \mathrm{C}$ for $1 \mathrm{~h}$ by keeping other reaction conditions constant. After five cycles, the decolorization rate decreases only approximately $9 \%$, from 56 to $47 \%$. This indicates that the PEC activity of YCT2 electrode has repeatability. Similar results are obtained in system of yttrium incorporated $\mathrm{TiO}_{2}$ supported ZSM-5. ${ }^{5}$ The reduction in the decolorization rate among the cycles may be explained by the formation of by-products and their accumulation in the cavities and on the active surface sites of the electrode. It was thought that the result was due to the decrease of the electrode surface for both photon absorption and MB adsorption.

Visible light photo-induced hydrophilicity. In order to test the hydrophilicity of the YCT series electrodes, the time of complete wetting for a drop of $\mathrm{MB}$ solution on the surface of electrode was determined. If the time of complete wetting is short this means good wetting and the contact angle lower, which is good hydrophilicity. Changes of the MB solution complete wetting on the surface of $\mathrm{Y}-\mathrm{CNT} / \mathrm{TiO}_{2}$ electrodes, induced by $8 \mathrm{~W}$ visible light irradiation, are shown in Fig. 9. Indoor condition, the time of complete wetting for non yttrium treated $\mathrm{CNT} / \mathrm{TiO}_{2}$ electrode is about 8 minutes. It reduces with adding of yttrium and approaches 30 seconds for YCT2. However under visible light irradiation, the time of complete wetting falls from 8 to 6.5 minutes and from 5.5 to 3.5 minutes for YCT0 and YCT4, respectively. The time of complete wetting changes slightly for other electrodes due to the original times are lower. The results showed that YCT1, YCT2 and YCT3 have good hydrophilicity indoor or under visible light irradiation. It was considered that the mechanism of hydrophilicity is different from PC activity, the electrons and holes are still produced but they react differently. The electrons tend to reduce the Ti (IV) cations to Ti (III) state; the holes oxidize $\mathrm{O}_{2}^{-}$anions. In this process oxygen atoms are ejected, creating oxygen vacancies. Water molecules can than occupy oxygen vacancies, producing adsorbed $\mathrm{OH}$ groups, which tend to make the surface hydrophilic. In spite of the different mechanisms of PC effect and hydrophilic effect, the correlation between the two is obvious. The photo-induced hydrophilicity of the electrode is closely related to the PC removal of organic substances from the electrode surface. The synergetic effect of photocatalysis and hydrophilicity can be understood as; because more $\mathrm{OH}$ groups can be adsorbed on the surface due to hydrophilicity, the PC activity is enhanced. So hydrophilicity can improve photocatalysis. On the other hand electrode surface can adsorb contaminated compounds which tend to convert the hydrophilic surface to the hydrophobic one. Photocatalysis can decompose the organic dirt on the electrode surface resulting in the restoration of hydrophilicity. This shows that photocatalysis can improve hydrophilicity and maintain this characteristic for long time. $\mathrm{Y}$ is supposed to enhance the hydrophilicity by taking an electron from $\mathrm{Ti}^{4+}$ to render it in $\mathrm{Ti}^{3+}$ state,

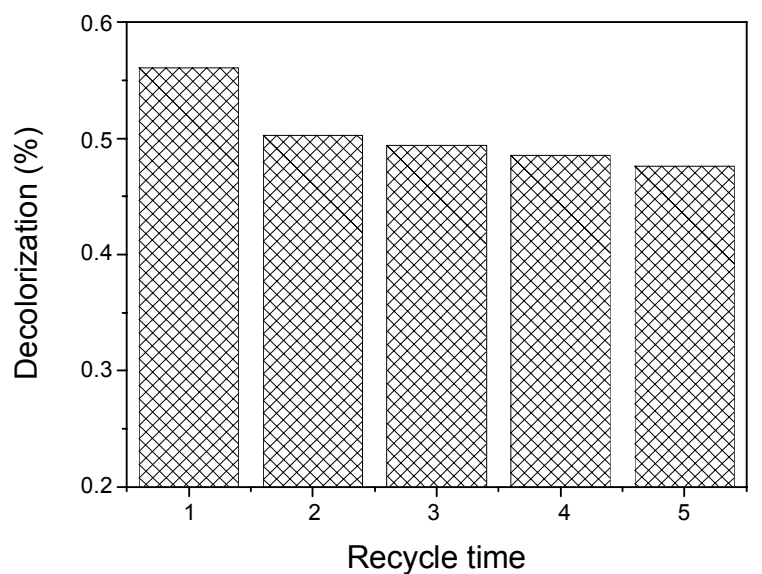

Figure 8. Effect of reuse of YCT2 electrode on the decolorization rate of $\mathrm{MB}$ in the aqueous solution with PEC reaction. (PEC: Visible light irradiation using the electrode with a potential of $6.0 \mathrm{~V}$ )

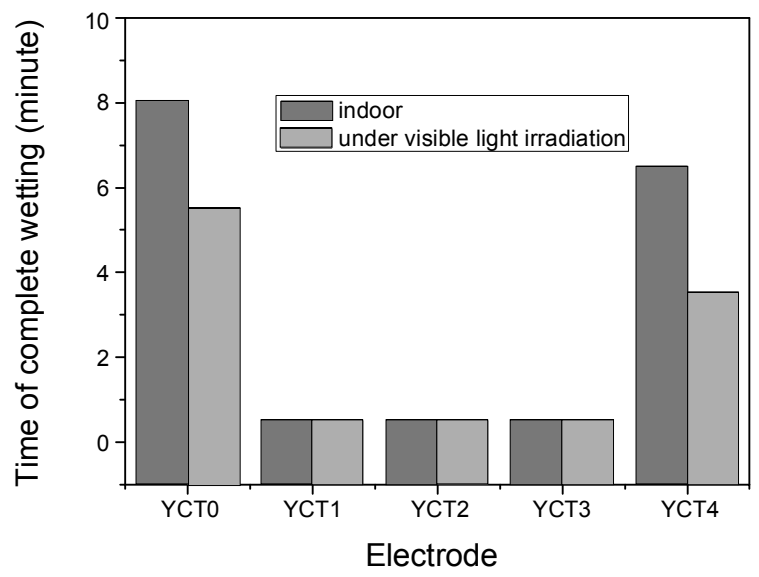

Figure 9. Visible light photo-induced change of the MB solution complete wetting on the surfaces of $\mathrm{Y}-\mathrm{CNT} / \mathrm{TiO}_{2}$ electrodes.

while holes remaining at the valence band of $\mathrm{TiO}_{2}$, thereby initiating the process for oxygen removal and hence hydrophilicity of the electrode.

\section{Conclusion}

In this study, we presented the fabrication and characterization of $\mathrm{CNT} / \mathrm{TiO}_{2}$ and $\mathrm{Y}-\mathrm{CNT} / \mathrm{TiO}_{2}$ composite electrodes. The BET surface area of $\mathrm{Y}-\mathrm{CNT} / \mathrm{TiO}_{2}$ composites decreased with an increase of $\mathrm{Y}$ component. XRD data revealed that the structure for the $\mathrm{Y}-\mathrm{CNT} / \mathrm{TiO}{ }_{2}$ composites showed a single anatase crystal phase. The TEM microphotographs of $\mathrm{CNT} / \mathrm{TiO}_{2}$ and $\mathrm{Y}-\mathrm{CNT} / \mathrm{TiO}_{2}$ composites showed that $\mathrm{TiO}_{2}$ particles were distributed uniformly in the CNTs network, and the Y particles were fixed on the surface of the CNTs, although they were partly aggregated. From the EDX data, the main elements such as $\mathrm{C}$, $\mathrm{O}$, Ti and $\mathrm{Y}$ existed. The $\mathrm{Y}-\mathrm{CNT} / \mathrm{TiO}_{2}$ samples have a higher PEC and PC degradation efficiency than that of the non-Y treated $\mathrm{CNT} / \mathrm{TiO}_{2}$ sample. The results demonstrated that the PEC degradation of MB solution could be attributed to synergetic effects of the photo-degradation of $\mathrm{TiO}_{2}$, the electron assis- 
tance of the CNT network, the enhancement of Y and a function of the applied potential. The morphology of Y in the Y-CNT/ $\mathrm{TiO}_{2}$ composites is an important factor. A loss of the catalytic activity ( $9 \%$ in 60 minutes) of YCT2 electrode was found after its first use. Hydrophilicity and photoactivity arise due to two different mechanisms, but they go side by side i.e. if one increases the other also increases or vice versa, this is due to interfacial nature of the two processes.

\section{Reference}

1. Chen, L. C.; Ho, Y. C.; Guo, W. S. Electrochim. Acta 2009, 54, 3884.

2. Hamal, D. B.; Klabunde. K. J. J. Colloid Interf. Sci. 2007, 311, 514.

3. Carp, O.; Huisman, C. L.; Reller, A. Prog. Solid State Chem. 2004, 32,33 .

4. Wang, W. D.; Serp, P.; Kalck, P. J. Mole. Catal. A Chem. 2005, 235,194

5. Neren O" kte, A.; O“ zge, Y. Appl. Catal. B: Environ. 2008, 85, 92. 6. Bhattachayya, A.; Kawi, S.; Ray, M. B. Catal. Today 2004, 98, 431.

7. Yoneyama, H.; Torimoto, T. Catal. Today 2000, 58, 133.

8. Fu, P. F.; Luan, Y.; Dai, X. G. J. Mole. Catal. A: Chem. 2004, 221, 81.

9. Oh, W. C.; Chen, M. L. Bull. Korean Chem. Soc. 2008, 29, 159.

10. Oh, W. C.; Jung, A. R.; Ko, W. B. J. Ind. Eng. Chem. 2007, 13, 1208.
11. Yang, S.; Zhu, W.; Li, X. Catal. Commun. 2007, 8, 2059.

12. Zhang, F. J.; Chen, M. L.; Oh, W. C. Environ. Eng. Res. 2009, 14, 32.

13. Zhang, F. J.; Chen, M. L.; Oh, W. C. Mater. Res. Soc. Korea 2008, 18,583 .

14. Kongkanand, A.; Kamat, P. V. ACS. Nano. 2007, 1, 13.

15. Choi, W.; Termin, A.; Hoffmann, M. R. J. Phys. Chem. 1994, 98 , 13669.

16. Fox, M. A.; Dulay, M. T. Chem. Rev. 1993, 93, 341.

17. Xu, A.; Gao, W. Y.; Liu, H. Q. J. Catal. 2002, 207, 151.

18. Jing, L. Q.; Sun, X. I.; Xin, B. F. J. Solid State Chem. 2004, 177, 3375 .

19. Shankar, M. V.; Cheralthan, K. K.; Arabindoo, B. J. Mole. Catal. 2004, 223, 195.

20. Shankar, M. V.; Anandan, S.; Venkatachalam, N. Chemosphere 2006, 63, 1014.

21. Zhang, Y. H.; Zhang, H. X.; Xu, Y. X. J. Mater. Chem. 2003, 13, 2261.

22. Liang, C. H.; Li, F. B.; Liu, C. S. Dyes Pigments 2008, 76, 477.

23. Lin, J.; Yu, J. C. J. Photochem. Photobiol. A: Chem. 1998, 116, 63.

24. Ismail, A. A. Appl. Catal. B: Environ. 2005, 58, 115.

25. Inagaki, M.; Hirose, Y.; Matsunaga, T. Carbon 2003, 41, 2619.

26. Oh, W. C.; Chen, M. L. J. Ceram. Process Res. 2008, 9, 100.

27. Zhang, X. W.; Zhou, M. H.; Lei, L. C. Carbon 2005, 43, 1700.

28. Christensen, P. A.; Curtis, T. P.; Egerton, T. A. Appl. Catal. B: Environ. 2003, 41, 371.

29. Ugarte, U.; Chatelain, A.; De Heer, W. A. Science 1996, $274,1897$.

30. Ajayan, P. M.; Iijima, S. Nature 1996, 361, 333. 